\title{
The influence of different sports on college students' physical health
}

\author{
Wusi Yan, Ying Li \\ Pingxiang University, Jiangxi 337055, China
}

\begin{abstract}
The effect and influence of different sports on College Students' physical health were discussed by five different sports after 15 weeks of special training. The results showed that the basketball can significantly improve the endurance, speed and sensitive quality; the effect of badminton on College Students' heart and lung function, speed, sensitivity and flexibility were significant; Qigong and aerobics major has significant effect to strength and flexibility quality; Sports dance can greatly improve the college students' heart and lung function and power quality.
\end{abstract}

Keywords: Different sports; college students; physical health; influence.

\section{Introduction}

College students are important human resources in the country, their physical health is related to their future time for national or social services. Recent reports of a lot of sudden death, once again for college students' physical health is a wake-up call, and from the results of College Students' physical health test in recent years, the overall health of the situation is also worrying, a lot of physical quality is a straight downward trend. Scientific and effective development of College Students' physical health is the goal of the common efforts of contemporary education and sports workers. The scientific experiments have proved that the appropriate physical exercise can strengthen people's health, but also prevent certain physical diseases. As one of the simplest, effective, the most direct and most economical way, sports has been accepted by more and more college students. Therefore, through the development of various forms of sports, to explore the different physical exercise program to college students' physical health of different influence and role, to provide guidance for college students' scientific fitness, but also to provide some reference and suggestions for sports workers in physical education reform and promote college students' physical health.

\section{2. research objects and methods}

\section{1 research object}

In different sports on the college students' physical health of influence as the research object, the main survey of the Pingxiang College Department of physical education 2012 and 2013 students majoring in a total of 92.

\section{2 research methods}

Documentation

By referring to the literature and information of College Students' physical health, this paper is to understand the current situation of College Students' physical health, and to lay a theoretical foundation for this study.

Experiment

Experimental object for Pingxiang College Sports Department of 2012 and 2013 students majoring in 92 people, each week course three times, each time class time is 90 minutes, lasted 15 weeks. Test content is specified in the "national student physical health standard" test items, respectively for height, weight, vital capacity, 1000 meters, 50 meters, grip strength, sit ups, jumping and sitting trunk flexion project, before and after the experiment tested once.

\section{Statistical method}

Using Excel and SPSS software to analyze and deal with the test results.

Comparative analysis

According to the test results, the data of the 5 classes of students before and after the experiment and use the method of variance and $\mathrm{T}$ test. 


\section{3. results and analysis}

\subsection{The comparison of various indicators before the experiment}

Before the experiment was carried out on all the students a fitness test, in order to detect whether there are differences between the students of constitution, in this study, we used the method of single factor analysis of variance to analyze the indexes. Taking student body mass index as an example.We can be seen from the results of table 1 , the boy $\mathrm{F}(0.53)<\mathrm{F}$ critical $(2.51)$, or $\mathrm{P}(0.71)>0.05$, girls $\mathrm{P}$ $=0.36>0.05$, from which can be thought before experiment every class student body mass index in the same level.

Table 1 Analysis of variance of body mass index before the experiment

\begin{tabular}{cccccccc}
\hline & Difference source & SS & df & MS & F & P-value & F crit \\
\hline Man & Between groups & 13.85911 & 4 & 3.464778 & 0.529983 & 0.71408 & 2.508695 \\
Female & Between groups & 11.8595 & 3 & 3.953166 & 1.144102 & 0.361413 & 3.238872 \\
\hline
\end{tabular}

\subsection{The index of comparative analysis before and after the experiment}

Table 2 The analysis of the index $\mathrm{T}$ test before and after the experiment ( $\mathrm{P}$ value)

\begin{tabular}{|c|c|c|c|c|c|c|c|c|}
\hline \multirow{2}{*}{ Project } & Gender & $\begin{array}{l}\text { body } \\
\text { mass } \\
\text { index }\end{array}$ & $\begin{array}{l}\text { FVC } \\
\text { body } \\
\text { index }\end{array}$ & $1000 \mathrm{~m}$ & $50 \mathrm{~m}$ & $\begin{array}{l}\text { Standing } \\
\text { long jump }\end{array}$ & $\begin{array}{l}\text { Weight } \\
\text { grip } \\
\text { index }\end{array}$ & $\begin{array}{l}\text { Sit and } \\
\text { Reach }\end{array}$ \\
\hline Basketball & Man & 0.43 & 0.24 & $0.04^{*}$ & $0.006^{* *}$ & $0.03^{*}$ & 0.34 & 0.08 \\
\hline \multirow{2}{*}{ Badminton } & Man & 0.24 & 0.06 & 0.37 & $0.03^{*}$ & $0.012^{*}$ & 0.13 & 0.13 \\
\cline { 2 - 9 } & Female & 0.33 & $0.015^{*}$ & 0.21 & $0.046^{*}$ & 0.06 & $0.03^{*}$ & $0.009^{* *}$ \\
\hline \multirow{2}{*}{ Qigong } & Man & 0.27 & 0.06 & 0.21 & 0.30 & 0.48 & $0.02^{*}$ & $0.001^{* *}$ \\
\cline { 2 - 9 } & Female & 0.36 & 0.46 & 0.50 & 0.38 & 0.19 & 0.37 & $0.03^{*}$ \\
\hline \multirow{2}{*}{ Aerobics } & Man & 0.39 & 0.06 & $0.002^{* *}$ & 0.08 & 0.11 & $0.011^{*}$ & $0.003^{* *}$ \\
\cline { 2 - 9 } & Female & 0.35 & 0.27 & 0.18 & 0.12 & 0.36 & $0.013^{*}$ & $0.03^{*}$ \\
\hline \multirow{2}{*}{$\begin{array}{c}\text { Sports } \\
\text { Dance }\end{array}$} & Man & 0.30 & $0.02^{*}$ & 0.12 & 0.35 & 0.13 & $0.004^{* *}$ & 0.26 \\
\cline { 2 - 9 } & Female & 0.43 & $0.009^{* *}$ & $0.013^{*}$ & 0.10 & 0.39 & $0.04^{*}$ & 0.44 \\
\hline
\end{tabular}

Note: * indicates $\mathrm{P}<0.05 ; * *$ indicates $\mathrm{P}<0.01$

The influence of different project on college students' body form

In determining a person's body shape evaluation usually use body mass index, the index, body mass index (BMI) is to use the weight (kg) divided by the square of the height (m), are commonly used to measure the degree of body fat and health of a standard. Student body mass index before and after the experiment $\mathrm{P}$ values were greater than 0.05 , it shows that different sports to student's body mass index did not change significantly. Perhaps the main cause is the subjects are college students around the age of 20, physical development has been mature, in a short period of time is usually not long, weight also won't have a larger change, therefore, there would be no significant difference in body mass index data.

The influence of different project on college students' cardiopulmonary function

The measure of the strength of a person's heart and lung function is the size of the vital capacity, in order to evaluate the heart and lung function of people with different body shapes, using the concept of vital capacity index. Vital capacity index is the ratio of vital capacity and body weight, which reflects the size of the oxygen uptake ability and the ability of discharging gas. It is also an important index in the comprehensive evaluation of students' physical fitness and the selection of athletes. After the test, each class of vital capacity index average rose, the badminton class girl index of lung capacity body show significant difference in statistics $(\mathrm{P}<0.05)$; Sports dance class boys show significant difference $(\mathrm{P}<0.05)$, while the girls are highly significant difference $(\mathrm{P}<0.01)$.

The influence of different project on college students' endurance quality

Through the comparison of different classes of students before and after the experiment, it is found that basketball has a significant difference on the endurance quality of boys. Dance sport to improve the quality of the girl's endurance also have significant differences, but the effect of aerobics is significantly better than badminton and fitness qigong, and sports dance can obviously increase the endurance, it is much better than the effect of health qigong and aerobics. 
The influence of different project speed quality for college students

We can see from the statistical results of table 2, the basketball to improve the speed quality of students has a highly significant difference $(\mathrm{P}<0.01)$, badminton for male and female students have significant differences $(\mathrm{P}<0.05)$, while the other three items to the student quality have no obvious effect, the speed of the test after each class quality has no significant difference between the speed.

The influence of different sensitive project on college students' quality

After test, besides sports dance, the rest of the project of long jump results have a certain role in promoting, but only basketball and badminton for boys jump performance have a significant effect, it also reflects the ball games to improve students' lower limbs explosive power and body harmony has great influence, and the standing long jump results have a significant impact. At the same time, the test after each class students standing long jump performance compare, playing basketball and badminton to improve the boys jump performance is significantly better than fitness qigong and sports dance $(\mathrm{P}<0.05)$, and apparently perform better in badminton girls in aerobics and sports dance class girls $(\mathrm{P}<0.05)$.

The influence of different project power quality for college students

Before the trial, the power of the male and female different class quality consistent before experiment, at the same level. And after test, qigong, aerobics and sports dance, three projects have significant differences, grip strength index weight gain for boys of sports dance is highly significant difference ( $\mathrm{P}<0.01)$, Relative to basketball, sports dance is better in terms of increasing power quality $(\mathrm{P}<0.05)$, while the effect of health qigong best $(\mathrm{P}<0.01)$.

The influence of different project flexible quality for college students

After test fitness qigong, aerobics has highly significant effect to the flexible quality of boys ( $\mathrm{P}<$ 0.01), the two projects at the same time also has significant effect to girls $(\mathrm{P}<0.05)$, flexible quality of badminton for girls also had a highly significant effect $(\mathrm{P}<0.01)$. And through the comparison between different classes after test study, the effect of the boys in the group health qigong is obviously better than basketball; Girls in the group health qigong to significantly better than badminton.

\section{4. conclusions and recommendations}

\section{1 conclusions}

through 5 different sports training and learning, students' physical form of a certain change, but this change did not reach statistical significant differences, from the effect, only basketball and sports dance class students' body mass index (BMI) has a significant difference, indicating the relative basketball sports, sports dance in improving the physical form of better results.

Different sports have a certain effect on the students' heart and lung function, which has a significant difference in badminton, the sports dance has a high degree of difference, and this effect is more obvious than the boys.

The basketball program has significant difference on the endurance quality of male college students, and there is a significant difference between the male and female students' endurance quality.

Basketball has a high degree of difference in the speed and quality of the male students, the badminton has a significant difference on the male and female students, while the other three items (Health Qigong, badminton, sports dance) have no significant effect on the students' quality.

although the basketball, badminton, fitness Qigong, aerobics on the students of the long jump results have a certain role, but only basketball and badminton have a significant impact on boys' long jump performance, and basketball and badminton to improve boys long jump performance is significantly better than the fitness, badminton, badminton is also significantly better than girls.

Fitness Qigong, bodybuilding exercises and the sports dance three projects of boys weight grip strength index have significant differences, which sports dance has highly significant differences; badminton, aerobics exercises and the sports dance of girls one minute sit ups have significant effect. 
Health Qigong, aerobics has a high degree of flexibility for boys and girls have a significant role, and badminton has a high degree of flexibility for girls, and through the effect of the boys in the group of fitness Qigong should be better than the basketball; girls group in the Health Qigong should be better than the badminton.

\section{2 recommendations}

different sports events for college students' physical health will have different effects and influence, some of the project will have a significant effect on the quality, such as badminton and sports can significantly improve heart and lung function, ball project can improve the speed and sensitivity, in a targeted to improve students' physical fitness, can be used to play a different role, so that the development of students physical fitness to achieve the effect of optimization.

in the full development of the principle of College Students' physical fitness is a balanced development of the process, different sports have a significant effect on the quality, but the quality of other aspects of the problem, in practice, should avoid different projects to develop students' physical limitations, reasonable combined with a variety of sports, or a sense of some of the quality of training, so as to promote the overall improvement of College Students' physique.

\section{References}

[1] AYing Ga. Different project options lesson "student physical health standard" test score of comparative study [J]. Journal of Beijing sport university, 2005, 28 (12)

[2] jin-tian Yang. Different project aerobic exercise to improve the students health fitness effect of comparative study [J]. Journal of hebei institute of sport, 2010, 24 (1)

[3] Guixia Cao. Different sports on college students' physique health effects of empirical research [J]. Journal of jilin institute of sport, 2013, 29 (3)

[4] QuanJun Wang. Option courses for different sports to promote female college students physical health of the experimental study [J]. Journal of yulin college journal, 2006 (4) 